\title{
Cost-effective larval diet mixtures for mass rearing of Anopheles arabiensis Patton (Diptera: Culicidae)
}

\author{
Nanwintoum Séverin Bimbilé Somda ${ }^{1,2,3^{*}}$, Kounbobr Roch Dabiré ${ }^{2}$, Hamidou Maiga ${ }^{1,2}$, Hanano Yamada ${ }^{1}$, \\ Wadaka Mamai ${ }^{1,4}$, Olivier Gnankiné ${ }^{3}$, Abdoulaye Diabaté $^{2}$, Antoine Sanon ${ }^{3}$, Jeremy Bouyer ${ }^{1}$ \\ and Jeremie Lionel Gilles ${ }^{1}$
}

\begin{abstract}
Background: Larval nutrition, particularly diet quality, is a key driver in providing sufficient numbers of high quality mosquitoes for biological control strategies such as the sterile insect technique. The diet currently available to mass rear Anopheles arabiensis, referred here to as the "IAEA diet", is facing high costs and difficulties concerning the availability of the bovine liver powder component. To promote more affordable and sustainable mosquito production, the present study aimed to find alternative diet mixtures. Eight cheaper diet mixtures comprised of varying proportions of tuna meal (TM), bovine liver powder (BLP), brewer's yeast (BY), and chickpea (CP) were developed and evaluated through a step by step assessment on An. arabiensis larvae and adult life history traits, in comparison to the IAEA diet which served as a basis and standard.

Results: Four mixtures were found to be effective regarding larval survival to pupation and to emergence, egg productivity, adult body size and longevity. These results suggest that these different diet mixtures have a similar nutritional value that support the optimal development of An. arabiensis larvae and enhance adult biological quality and production efficiency, and thus could be used for mass rearing.

Conclusions: Our study demonstrated that four different diet mixtures, 40 to 92\% cheaper than the IAEA diet, can result in a positive assessment of the mosquitoes' life history traits, indicating that this mosquito species can be effectively mass reared with a significant reduction in costs. The mixture comprised of TM + BY + CP is the preferred choice as it does not include BLP and thus reduces the cost by $92 \%$ compared to the IAEA diet.
\end{abstract}

Keywords: Larval diet, Anopheles arabiensis, Tuna meal, Bovine liver powder, Brewer's yeast, Chickpea, SIT biological control

\section{Background}

Malaria remains a major public health burden, especially in sub-Saharan Africa where $88 \%$ of all reported cases and $90 \%$ of malaria related deaths occurred in 2015 [1]. Anopheles arabiensis is one of the main vectors in Africa. This species is known to have a wide distribution by adapting to various ecological zones such as desert savannah, forested areas [2] and urban areas as found in

\footnotetext{
* Correspondence: nansevbis@gmail.com

${ }^{1}$ Insect Pest Control Laboratory, International Atomic Energy Agency, Joint FAO/IAEA Division of Nuclear Techniques in Food and Agriculture, Vienna, Austria

${ }^{2}$ Institut de Recherche en Sciences de la Santé/Direction Régionale de I'Ouest, Bobo-Dioulasso, Burkina Faso

Full list of author information is available at the end of the article
}

Burkina Faso [3, 4]. Described as a zoophilic, exophagic and exophilic species, in comparison to An. gambiae [5], $A n$. arabiensis displays genetic plasticity and adapts its feeding and resting behaviours following the biotope conditions $[6,7]$. This plasticity, coupled with resistance mechanisms $[4,8]$ allows it to avoid insecticide-based control methods, including the use of long-lasting insecticidetreated nets and indoor residual spraying $[6,8,9]$ which are the main methods that are currently being relied upon for malaria control. To better control this species, biological control tactics, including the sterile insect technique (SIT), appear to be promising alternatives [10].

SIT is based on a continuous release of laboratoryreared, sterile males into a target area, where they 
compete with wild males to mate with wild females, resulting in sterile mating. One recommendation to control An. arabiensis in Sudan entails the release of 1 million sterile males per day [11]. This requires a sufficient number of efficient males; high quality yet cost effective mass rearing is therefore mandatory. Mosquito larvae ingest nutrients not only to complete their development but also to accumulate reserves for adulthood [12]. Indeed, the innate qualities of the mosquito, including size, flight and mating capabilities, fecundity, and longevity are known to largely depend on the conditions throughout the immature, i.e. early developmental stages, particularly on the quality and amount of available larval food [13-19]. Larval diet is, therefore, one of the key drivers in mass release techniques.

Mosquitoes require proteins or amino acids, fatty acids, nucleic acids, sterols and vitamins for normal or optimal larval development to adulthood [20]. In the natural environment, food sources of Anopheles species include microorganisms and detritus [21]. For laboratory rearing, artificial larval diets are a mix of ingredients from animals, plants and microorganisms. Among such ingredients, tuna meal, bovine liver powder, soy meal, chickpeas, brewer's yeast are known to be effective. However, their effectiveness relies upon their proportions within the diets and is dependent upon the mosquito species [22-25]. Mosquito mass rearing requires cost-effective production and diet ingredients are the most costly components of the process. Therefore, mass production would become more affordable and suitable, if larval feeding can be minimized while ensuring that the quality of insects produced remains high. In order to establish optimal $A n$. arabiensis larval diets, the present study assesses different diet combinations, including more globally accessible ingredients, i.e. tuna meal (TM), bovine liver powder (BLP), chickpeas (CP) and brewer's yeast (BY), on larvae and adult life history traits. Taking into account the accessibility of the ingredients, the diet mixtures were aimed at minimizing the proportion of BLP, the most expensive component, while maximizing the amount of TM and integrating $\mathrm{CP}$ and $\mathrm{BY}$. Initially, eight mixtures were created and assessed on An. arabiensis larval developmental parameters first without vitamin mix (VM) (Vanderzant vitamin) as an additive and secondly with the additive. Finally, four more promising mixtures were selected and evaluated on both larval and adults life history traits.

\section{Methods}

\section{Mosquito strain}

The $A n$. arabiensis strain used for all experiments was acquired from Dongola in the Northern state of Sudan in 2005 and has since been maintained at the Insect Pest Control Laboratory (IPCL) of the Joint FAO/IAEA Division of Nuclear Techniques in Food and Agriculture, Seibersdorf, Austria. A mixture (10 g/l) of $50 \%$ of TM,
50\% BLP plus VM (4.6 g/l) [23] was used for larval feeding for routine colony maintenance. This mixture was used as a control in the present study. Larvae and adults were routinely reared in a climate-controlled room at $27 \pm 1{ }^{\circ} \mathrm{C}, 70 \pm 10 \%$ relative humidity, $12: 12 \mathrm{~h}$ light: dark, including $1 \mathrm{~h}$ dusk and $1 \mathrm{~h}$ dawn. Adults were loaded into $30 \times 30 \times 30 \mathrm{~cm}$ cages (BugDorm- $1 \mathrm{H}$; MegaView, Taichung, Taiwan) with constant access to a 5\% sugar solution. Defrosted bovine blood meals were provided to females for egg production.

\section{Diet ingredients, suppliers and costs}

The supplier and the cost of each diet ingredient used in this study are shown in Table 1 . The prices are estimated per $100 \mathrm{~kg}$ to take into account potential price reductions in the case of bulk orders expected in mass rearing facilities.

\section{Bioassays}

Experiments were performed at two levels using $90 \mathrm{~mm}$ diameter disposable polystyrene Petri dishes and secondly, plastic trays $(40 \times 29 \times 8 \mathrm{~cm})$. Larvae were fed with a $1 \%(10 \mathrm{~g} / \mathrm{l})$ diet solution in all experiments.

\section{Experiment 1: Evaluation of the diet mixtures without vitamin mix on An. arabiensis larval development}

Eight mixtures (hereafter Mix 1 to Mix 8) were developed by increasing the amount of TM and reducing the amount of BLP or replacing it with cheaper and more accessible ingredients, CP and BY. Each ingredient, except vitamin mix, was ground using a planetary ball mill PM100 (Retsch ${ }^{\circ}$ GMBH, Haan, Germany). The final particle size of the ingredient powder was between 50 and $150 \mu \mathrm{m}$. The effect of each diet mixture was first assessed without VM, in comparison to the control (Mix 0 ) using Petri dishes. The ingredient proportions in each diet mixture are shown in Table 2. Thirty-two first-instar larvae (L1) less than $4 \mathrm{~h}$ old were transferred into $90 \mathrm{~mm}$ diameter disposable polystyrene Petri dishes containing $32 \mathrm{ml}$ of deionized water. Five replicates were performed for each diet mixture. In order to better assess the nutritional value of the diet mixtures on larval development, the experiment was performed in food stress conditions (low food amount/larva/day). $0.32 \mathrm{ml}$ of $1 \%$ diet solution, equivalent to $1 \mathrm{mg} /$ larva/day, was added daily to each Petri dish from day 0 to day 9 . The Petri dishes were checked every $24 \mathrm{~h}$ and any pupae were collected, counted and transferred into small plastic cups for emergence. The date of emergence was recorded and the emerged mosquitoes counted. Larval development time and survival rates from L1 to pupa and to adult were also determined. 
Table 1 Diet ingredient price per $100 \mathrm{~kg}$ and supplier

\begin{tabular}{|c|c|c|c|c|c|c|}
\hline Ingredient & Code & Supplier & $\begin{array}{l}\text { Price of } 100 \mathrm{~kg} \\
\text { (USD) }\end{array}$ & $\begin{array}{l}\text { Cost ratio compared } \\
\text { with BLP }\end{array}$ & $\begin{array}{l}\text { Proportion }(w / w) \text { in the IAEA } \\
\text { diet }(\%)\end{array}$ & $\begin{array}{l}\text { Account in the IAEA diet } \\
\text { cost (\%) }\end{array}$ \\
\hline $\begin{array}{l}\text { Bovine liver } \\
\text { powder }\end{array}$ & BLP & $\begin{array}{l}\text { MP Biomedicals, } \\
\text { Solon, OH }\end{array}$ & 6300 & 1.00 & 50 & 98.75 \\
\hline Tuna meal & TM & T.C. Union Agrotech & 80 & 78.75 & 50 & 1.25 \\
\hline Breyer's yeast & BY & MP Biomedicals & 1000 & 6.30 & 0 & 0 \\
\hline Chickpea flour & $\mathrm{CP}$ & $\begin{array}{l}\text { TRS Asian's fitness } \\
\text { foods }\end{array}$ & 328.26 & 19.19 & 0 & 0 \\
\hline $\begin{array}{l}\text { Vanderzant } \\
\text { vitamin }\end{array}$ & VM & BioServ & 2800 & 2.25 & Additive & - \\
\hline
\end{tabular}

Experiment 2: Evaluation of the diet mixtures supplied with vitamin mix on An. arabiensis larval development

The diet mixtures described in experiment 1 were supplemented with vitamin mix and tested using Petri dishes and following the same protocol. An equal amount of VM (corresponding to $4.6 \mathrm{~g} / \mathrm{l}$ of the mixture solution) was added to each diet mixture. To avoid confusion with the previous diet mixtures, "Mix 0 to Mix 8" were coded as "Mix 10 to Mix 18", respectively, in experiment 2. Larval development time and survival rates from L1 to pupa and to adult were recorded.

\section{Experiment 3: Evaluation of the most promising diet mixtures on An. arabiensis larvae and adult life history traits}

From assays described above, four promising diet mixtures were selected based on the time from L1 to pupa and the larval survival rate from L1 to adult and tested using plastic trays $(40 \times 29 \times 8 \mathrm{~cm})$. Four hundred firstinstar larvae (L1) were transferred into each tray containing $1 \mathrm{l}$ of deionized water. A $1 \%$ diet solution was added daily to each respective tray from day 0 (D0) until day 7 (D7) as follows: $8 \mathrm{ml}$ on D0 and D1, $16 \mathrm{ml}$ on D2 and D3, $32 \mathrm{ml}$ on D4 and D5, and $64 \mathrm{ml}$ on D6 and D7. Five replicates were performed for each diet mixture. Larval development time and survival rates from L1 to pupa and to adult were recorded. Adult longevity was evaluated from 3 replicates of each diet mixture. To evaluate this parameter, 3 standard rearing cages $(30 \times$ $30 \times 30 \mathrm{~cm}$ ) were stocked with 50 males and 50 females aged 1 day from the same cohort. Mortality was checked every 2 days until all of the mosquitoes were dead. Dead mosquitoes were removed and counted by sex. Fecundity was also assessed on the same mosquitoes whose longevity was followed. This allowed the sample size for each parameter to be increased, whilst considering pupae produced on the same day and evaluating the potential longevity of the mosquitoes taking into account reproduction cost including mating, blood-feeding and egg production. Defrosted cattle blood was provided to females on the third and the fourth day post-emergence, using the blood-feeding system described by Damiens et al. [26]. Oviposition cups were placed inside the cages on the sixth and the seventh day and eggs were collected on the seventh and the eighth day. Pictures of the egg papers were captured and eggs were counted using Microsoft Paint 2013. Wing length (left wing) was considered as an indicator of adult body size; measurements were taken from 10 males and 10 females randomly selected from each of the 5 replicates of each treatment.

\section{Statistical analysis}

The R Software version 3.2.5 [27] was used to perform all statistical analyses and to make the graphs. We used binomial generalized linear mixed models fit by maximum likelihood (Laplace approximation) with the larval survival rates to pupa and to adult from the initial number of L1 as response variables, diet mixture as fix effects and the replicate as a random effect. We used a Gaussian linear mixed-effects model with the larval development times from L1 to pupation and to emergence assigned as response variables, the diet mixture as fix effect and the repeats as random effects. The survival of adult mosquitoes reared on the different diets mixtures

Table 2 Ingredient proportions (\%) in each diet mixture

\begin{tabular}{|c|c|c|c|c|c|c|c|c|c|}
\hline Ingredient/ Mixture & Mix 0 & Mix 1 & Mix 2 & Mix 3 & Mix 4 & Mix 5 & Mix 6 & Mix 7 & Mix 8 \\
\hline Tuna meal (TM) (\%) & 50 & 70 & 70 & 70 & 70 & 50 & 100 & 25 & 50 \\
\hline Bovine liver powder (BLP) (\%) & 50 & 30 & 15 & 15 & 0 & 20 & 0 & 25 & 20 \\
\hline Brewer's yeast (BY) (\%) & 0 & 0 & 15 & 0 & 15 & 15 & 0 & 25 & 20 \\
\hline Chickpea (CP) (\%) & 0 & 0 & 0 & 15 & 15 & 15 & 0 & 25 & 10 \\
\hline Vitamin mix (VM) (4.6 g/l) & 0 & 0 & 0 & 0 & 0 & 0 & 0 & 0 & 0 \\
\hline Total (100\%) & 100 & 100 & 100 & 100 & 100 & 100 & 100 & 100 & 100 \\
\hline
\end{tabular}


was analyzed using Kaplan-Meier survival curves. Survival curves were compared using the coxph model where the diet mixture is the explanatory variable and survival rate is the response variable.

\section{Results}

Experiment 1: Evaluation of the diet mixtures without vitamin mix on An. arabiensis larval development

All of the diet mixtures were tested in food stress conditions (defined as the allotment of larval diet amounts less than the daily required amount per larvae) resulting in variable larval development times and survival rates (Fig. 1a, b). Overall, both larval survival rates to pupa and to adult were less than $50 \%$ in all treatments, including the IAEA diet (Fig. 1c, d). Larval survival rates to pupa ranged between 10 and $39 \%$ and emergence rates between 4 and $37 \%$. The lowest rates were observed with the mixture containing only tuna meal (Mix 6) and the highest rates were observed with the mixture made of an equal amount of each of the four ingredients (Mix 7). The generalized linear mixed model with Mix 0 as the control level revealed different effects of the diets on mosquito life history traits as summarized in Tables 3 and 4. Indeed, for both larval survival rates to pupa and to adult, only Mix 5 and Mix 7 lead to significantly higher rates $(P<0.05)$ and Mix 6 reduced these rates of development $(P<0.05)$. The time from L1 to both pupa and adult was longer when using Mix 1 to Mix $5(P<$ $0.05)$ and was similar between Mix 7 and Mix $8(P>$ 0.05). Considering the slopes in the larval development time from L1 to pupation, the control, although different, was closer by order to Mix 5, Mix 3, Mix 2 and Mix 1. Mix 7, which was similar to the control in the larval development time and had a higher larval survival rate, was the most promising overall, followed by Mix 8 which was similar to the control in all parameters. Mix 6 , which prolonged time to pupa $(P<0.05)$ and led to the lowest $(P<0.05)$ larval survival rate, was the least optimal diet. Hence, taking larval development time and survival rate into account, the tested diet mixtures could be classified by order of most to least promising as Mix 7, Mix 8, Mix 5, Mix 4, Mix 3, Mix 2, Mix 1 and Mix 6.

\section{Experiment 2: Evaluation of the diet mixtures supplied with vitamin mix on An. arabiensis larval development}

The larval developmental parameters using diets supplemented with vitamin mix are shown in Fig. 2a-d. In all treatments, supplementation with vitamin mix added positive effects on all parameters. The highest larval survival rates to pupa and to adult were observed with Mix 12 . The shortest development times from L1 to pupa and to adult were observed with the control (Mix 10) and the longest with Mix 11. Differences between the diets on mosquito life history traits were observed from the generalized linear mixed model with Mix 10 (control) used as a reference level (Tables 5 and 6). The control showed a shorter time from L1 to pupa and to adult than Mix 11 to Mix $16(P<0.05)$ but was similar to Mix $18(P>0.05)$. Mix 17 resulted in a similar time to pupation as the control $(P$ $=0.0538)$ but a longer time to emergence $(P=0.0109)$. Based on the slope values in time to pupa, the tested diets could be ranged by increasing value as by order of effectiveness as Mix 18, Mix 17, Mix 12, Mix 15, Mix 14, Mix 16, Mix 13 and Mix 11. In comparison to the control, only Mix $16(100 \%$ tuna meal $+\mathrm{VM})$ resulted in a lower larval survival rates to pupa and adult $(P<0.05)$ and Mix 11 showed similar effects $(P>0.05)$. Mix 12, Mix 13, Mix 14, Mix 15, Mix 17 and Mix 18 resulted in higher larval
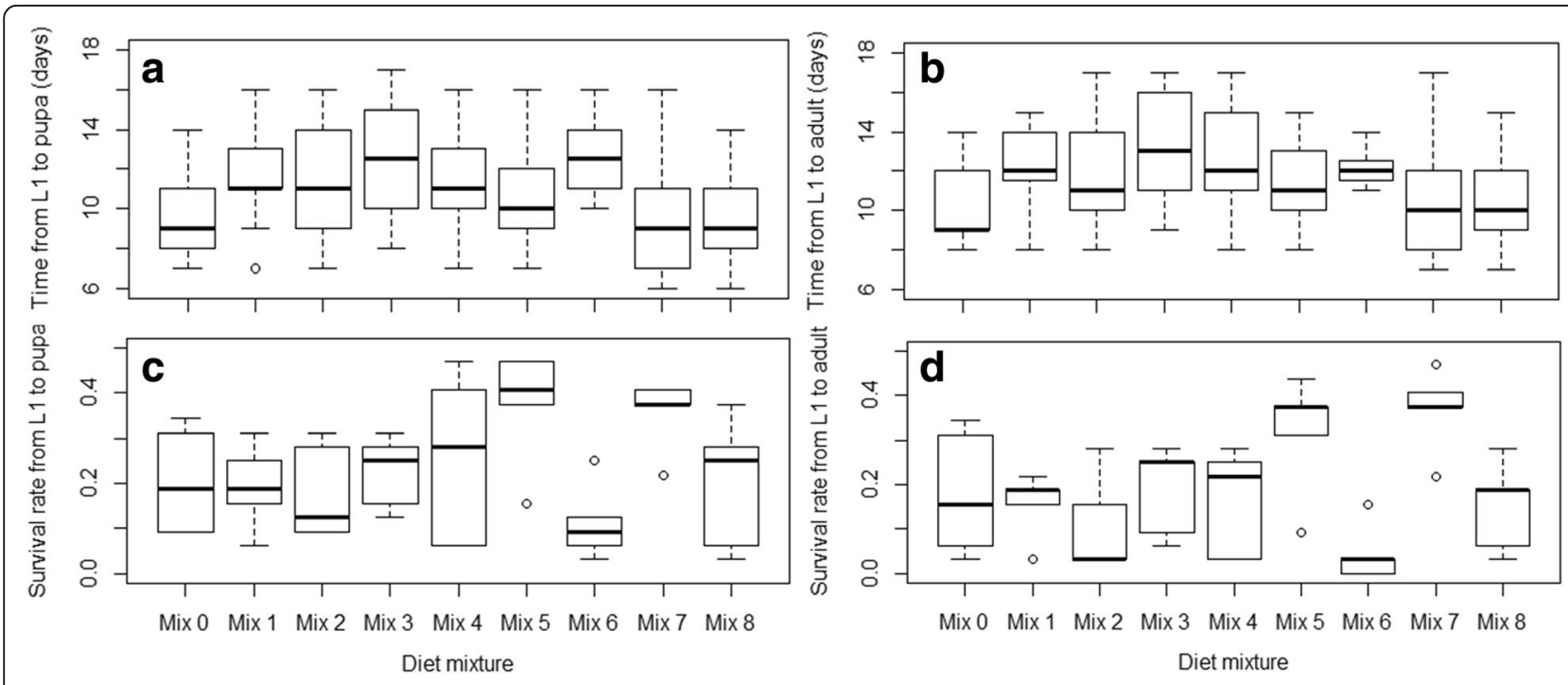

Fig. 1 Time to pupation (a) and emergence (b) and survival rates to pupa (c) and to adult (d) using diets without vitamin mix 
Table 3 Effects of diets mixtures without vitamin mix on An. arabiensis larval development times

\begin{tabular}{|c|c|c|c|c|c|c|}
\hline & & Value & SE & $d f$ & $t$-value & $P$-value \\
\hline \multirow[t]{9}{*}{ Time from L1 to pupa } & (Intercept) & 9.3961 & 0.4258 & 328 & 22.0672 & $<0.0001^{* * *}$ \\
\hline & Mix 1 & 2.2485 & 0.6472 & 328 & 3.4742 & $0.0006^{* * *}$ \\
\hline & Mix 2 & 2.1917 & 0.5891 & 328 & 3.7206 & $0.0002^{* * *}$ \\
\hline & Mix 3 & 3.2251 & 0.5561 & 328 & 5.7978 & $<0.0001^{* * *}$ \\
\hline & Mix 4 & 1.9290 & 0.5337 & 328 & 3.6143 & $0.0003^{* * *}$ \\
\hline & Mix 5 & 1.1373 & 0.5020 & 328 & 2.2658 & $0.0241^{* *}$ \\
\hline & Mix 6 & 3.1756 & 0.6707 & 328 & 4.7351 & $<0.0001^{* * *}$ \\
\hline & Mix 7 & -0.2271 & 0.5006 & 328 & -0.4537 & 0.6504 \\
\hline & Mix 8 & 0.1649 & 0.5370 & 328 & 0.3071 & 0.7590 \\
\hline \multirow[t]{9}{*}{ Time from L1 to adult } & (Intercept) & 10.1577 & 0.4283 & 266 & 23.7155 & $<0.0001^{* * *}$ \\
\hline & Mix 1 & 2.1884 & 0.6496 & 266 & 3.3691 & $0.0009^{* * *}$ \\
\hline & Mix 2 & 1.9216 & 0.6740 & 266 & 2.8509 & $0.0047^{* *}$ \\
\hline & Mix 3 & 3.0929 & 0.5684 & 266 & 5.4417 & $<0.0001^{* * *}$ \\
\hline & Mix 4 & 2.3120 & 0.5785 & 266 & 3.9968 & $0.0001^{* * *}$ \\
\hline & Mix 5 & 1.3320 & 0.4974 & 266 & 2.6780 & $0.0079^{* *}$ \\
\hline & Mix 6 & 1.7262 & 0.9162 & 266 & 1.8841 & 0.0606 \\
\hline & Mix 7 & -0.0946 & 0.4934 & 266 & -0.1917 & 0.8481 \\
\hline & Mix 8 & 0.6032 & 0.5495 & 266 & 1.0977 & 0.2733 \\
\hline
\end{tabular}

Abbreviations: $S E$ standard error, $d f$ degrees of freedom

${ }^{* *} P<0.01,{ }^{* *} P<0.001$

Table 4 Effects of diets mixtures without vitamin mix on An. arabiensis larval survival rates

\begin{tabular}{|c|c|c|c|c|c|}
\hline & & Estimate & SE & $z$-value & $\operatorname{Pr}(>|z|)$ \\
\hline \multirow[t]{9}{*}{ Survival rate from L1 to pupa } & (Intercept) & -1.3704 & 0.2330 & -5.881 & $4.09 \mathrm{e}-09^{* * *}$ \\
\hline & Mix 1 & -0.0790 & 0.2810 & -0.281 & 0.7784 \\
\hline & Mix 2 & -0.1621 & 0.2847 & -0.569 & 0.5692 \\
\hline & Mix 3 & 0.1123 & 0.2736 & 0.411 & 0.6813 \\
\hline & Mix 4 & 0.2859 & 0.2680 & 1.067 & 0.2859 \\
\hline & Mix 5 & 0.8497 & 0.2564 & 3.314 & $0.0009^{* * *}$ \\
\hline & Mix 6 & -0.7248 & 0.3186 & -2.275 & $0.0229^{*}$ \\
\hline & Mix 7 & 0.8768 & 0.2561 & 3.424 & $0.0006^{* * *}$ \\
\hline & Mix 8 & -0.0391 & 0.2794 & -0.140 & 0.8887 \\
\hline \multirow[t]{9}{*}{ Survival rate from L1 to adult } & (Intercept) & -1.4992 & 0.2330 & -6.435 & $1.23 \mathrm{e}-10^{* * *}$ \\
\hline & Mix 1 & -0.1568 & 0.3010 & -0.521 & 0.6025 \\
\hline & Mix 2 & -0.5621 & 0.3306 & -1.700 & 0.0891 \\
\hline & Mix 3 & 0.0646 & 0.2903 & 0.222 & 0.8240 \\
\hline & Mix 4 & -0.0328 & 0.2997 & -0.110 & 0.9128 \\
\hline & Mix 5 & 0.8163 & 0.2695 & 3.029 & $0.0024^{* *}$ \\
\hline & Mix 6 & -1.5293 & 0.4387 & -3.486 & $0.0005^{* * *}$ \\
\hline & Mix 7 & 0.9769 & 0.26475 & 3.690 & $0.0002^{* * *}$ \\
\hline & Mix 8 & -0.1893 & 0.3039 & -0.623 & 0.5334 \\
\hline
\end{tabular}



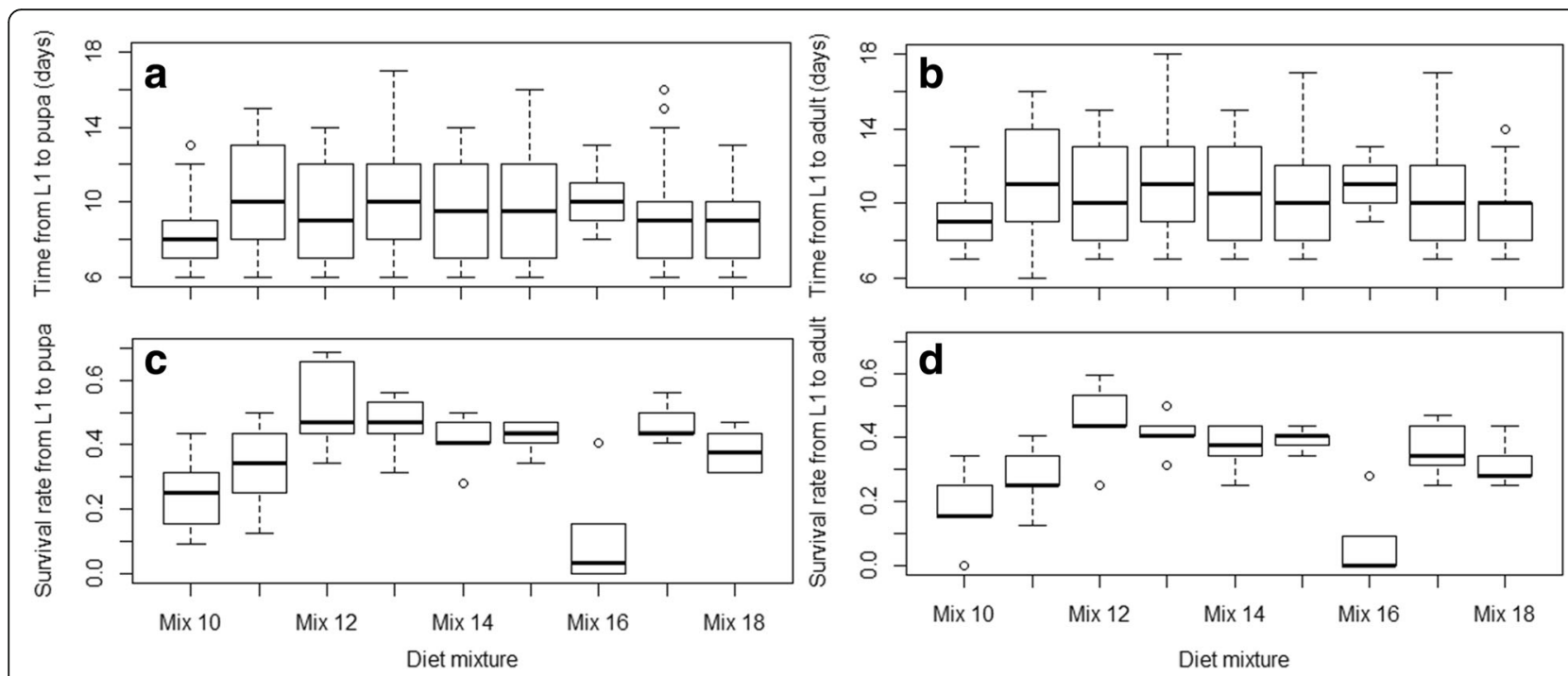

Fig. 2 Time to pupation (a) and emergence (b) and survival rates to pupa (c) and to adult (d) using diets with vitamin mix

survival rates $(P<0.05)$. Considering the slopes in the larval survival rates to adult and in the times to pupation, the five most promising mixtures are listed respectively by decreasing value of time to pupation as Mix 12, Mix 13, Mix 15, Mix 14 and Mix 17 and by increasing value of survival rate as Mix 18, Mix 17, Mix 15, Mix 12, and Mix 14. Taking both into account, Mix 17, Mix 15, Mix 12, Mix 14 were selected and further assessed on a larger scale using plastics trays $(40 \times 29 \times 8 \mathrm{~cm})$.

\section{Experiment 3: Evaluation of promising diet mixtures on An. arabiensis larval and adult life history traits}

Four diet mixtures were selected and tested at larger scale using plastic trays $(40 \times 29 \times 8 \mathrm{~cm})$ : Mix $12: 70 \%$

Table 5 Effects of diets mixtures supplemented with vitamin mix on An. arabiensis larval development times

\begin{tabular}{|c|c|c|c|c|c|c|}
\hline & & Value & SE & $d f$ & t-value & $P$-value \\
\hline \multirow[t]{9}{*}{ Time from L1 to pupa } & (Intercept) & 8.3627 & 0.3903 & 524 & 21.4270 & $<0.0001^{* * *}$ \\
\hline & Mix 11 & 2.1212 & 0.4975 & 524 & 4.2636 & $<0.0001^{* * *}$ \\
\hline & Mix 12 & 1.1275 & 0.4566 & 524 & 2.4697 & $0.0138^{*}$ \\
\hline & Mix 13 & 1.7774 & 0.4650 & 524 & 3.8225 & $0.0001 * * *$ \\
\hline & Mix 14 & 1.3036 & 0.4746 & 524 & 2.7469 & $0.0062^{* *}$ \\
\hline & Mix 15 & 1.2633 & 0.4710 & 524 & 2.6818 & $0.0076^{* *}$ \\
\hline & Mix 16 & 1.7277 & 0.6634 & 524 & 2.6043 & $0.0095^{* *}$ \\
\hline & Mix 17 & 0.8956 & 0.4634 & 524 & 1.9328 & 0.0538 \\
\hline & Mix 18 & 0.5323 & 0.4801 & 524 & 1.1086 & 0.2381 \\
\hline \multirow[t]{9}{*}{ Time from L1 to adult } & (Intercept) & 8.9646 & 0.4332 & 439 & 20.6940 & $<0.0001^{* * *}$ \\
\hline & Mix 11 & 2.1465 & 0.5579 & 439 & 3.8472 & $0.0001^{* * *}$ \\
\hline & Mix 12 & 1.4002 & 0.5091 & 439 & 2.7501 & $0.0062^{* *}$ \\
\hline & Mix 13 & 2.0184 & 0.5164 & 439 & 3.908216 & $0.0001^{* * *}$ \\
\hline & Mix 14 & 1.5910 & 0.5284 & 439 & 3.010714 & $0.0280^{*}$ \\
\hline & Mix 15 & 1.3174 & 0.5198 & 439 & 2.534521 & $0.0116^{*}$ \\
\hline & Mix 16 & 1.8924 & 0.8177 & 439 & 2.314426 & $0.0211^{*}$ \\
\hline & Mix 17 & 1.3656 & 0.5343 & 439 & 2.556125 & $0.0109^{*}$ \\
\hline & Mix 18 & 0.7888 & 0.5394 & 439 & 1.462174 & 0.1444 \\
\hline
\end{tabular}


Table 6 Effects of diets mixtures supplemented with vitamin mix on An. arabiensis larval survival rates

\begin{tabular}{llllll}
\hline & & Estimate & SE & $z$-value & $\operatorname{Pr}(>|z|)$ \\
\hline Survival rate from & (Intercept) & -1.0986 & 0.1826 & -6.017 & $1.77 \mathrm{e}-09^{* * *}$ \\
& Mix 11 11 & 0.3961 & 0.2481 & 1.597 & 0.1104 \\
& Mix 12 & 1.1736 & 0.2416 & 4.858 & $1.19 \mathrm{e}-06^{* * *}$ \\
& Mix 13 & 0.9483 & 0.2418 & 3.922 & $8.79 \mathrm{e}-05^{* * *}$ \\
& Mix 14 & 0.7450 & 0.2432 & 3.064 & $0.0022^{* *}$ \\
& Mix 15 & 0.7963 & 0.2427 & 3.281 & $0.0010^{* *}$ \\
Survival rate from & Mix 16 & -0.9057 & 0.3051 & -2.969 & $0.0030^{* *}$ \\
L1 to adult & Mix 17 & 0.9734 & 0.2417 & 4.027 & $5.65 \mathrm{e}-05^{* * *}$ \\
& Mix 18 & 0.6144 & 0.2446 & 2.512 & $0.0120^{*}$ \\
& Mix 11 11 & 0.5316 & 0.2737 & 1.942 & 0.0521 \\
& Mix 12 & 1.3531 & 0.2640 & 5.125 & $2.97 \mathrm{e}-07^{* * *}$ \\
& Mix 13 & 1.1555 & 0.2638 & 4.380 & $1.19 \mathrm{e}-05^{* * *}$ \\
& Mix 14 & 0.9544 & 0.2653 & 3.597 & $0.0003^{* * *}$ \\
& Mix 15 & 1.0415 & 0.2637 & 3.949 & $7.84 \mathrm{e}-05^{* * *}$ \\
& Mix 16 & -1.0437 & 0.3650 & -2.859 & $0.0042^{* *}$ \\
& Mix 17 & 1.0380 & 0.2680 & 3.873 & $0.0001^{* * * *}$ \\
& Mix 18 & 0.7569 & 0.2693 & 2.811 & 0.0049 ** \\
\hline
\end{tabular}

Abbreviations: SE standard error, $d f$ degrees of freedom ${ }^{*} P<0.05,{ }^{* *} P<0.01,{ }^{* * *} P<0.001$
$\mathrm{TM}+15 \% \mathrm{BLP}+15 \% \mathrm{BY}+\mathrm{VM} ; \mathrm{Mix} 14: 70 \% \mathrm{TM}+$ $15 \%$ BY +15\% CP + VM; Mix 15: $50 \% \mathrm{TM}+20 \%$ BLP $+15 \%$ BY +15\% CP + VM; Mix 17: $25 \% \mathrm{TM}+25 \%$ $\mathrm{BLP}+25 \% \mathrm{BY}+25 \% \mathrm{CP}+\mathrm{VM}$.

\section{Effect of four selected diets on An. arabiensis larval} development and adult body size, egg production and survival

The larval and adult developmental parameters resulting from each diet mixture and the proportion of price reduction in relation to the control are summarized in Fig. 3a-d. These diet mixtures cost $40-92 \%$ less than the control. Overall, survival rates from L1 to pupa ranged between 75 and $86 \%$, and survival rates from L1 to adult ranged between 70 and $83 \%$. The assessed diet mixtures resulted in similar or better larval survival rates than the control (Table 7). Indeed, all treatments were similar to the control with respect to survival rates from L1 to pupa $(P>0.05)$ and resulted in higher survival rates from L1 to adult $(P<0.05)$, except for Mix $15(P=0.1729)$. A significant difference was observed in the effects of the assessed mixtures on larval development times (Table 8). Mix 14 and Mix 15 resulted in a shorter time from L1 to pupation while Mix 12 and Mix 17 were similar to the control. Regarding the time to emergence, Mix 12 and Mix 14 resulted in longer times $(P<0.05)$, Mix 15 in a shorter time $(P<0.0009)$ and time to emergence for Mix 17 was similar to the control $(P=0.1080)$. Considering the times from L1 to pupa and the survival rates from L1 to adult, Mix 14 would be the preferred choice. Adult wing length and egg production following the diet mixture are shown in Fig. 4a-c. No significant differences were observed between the treatments and the
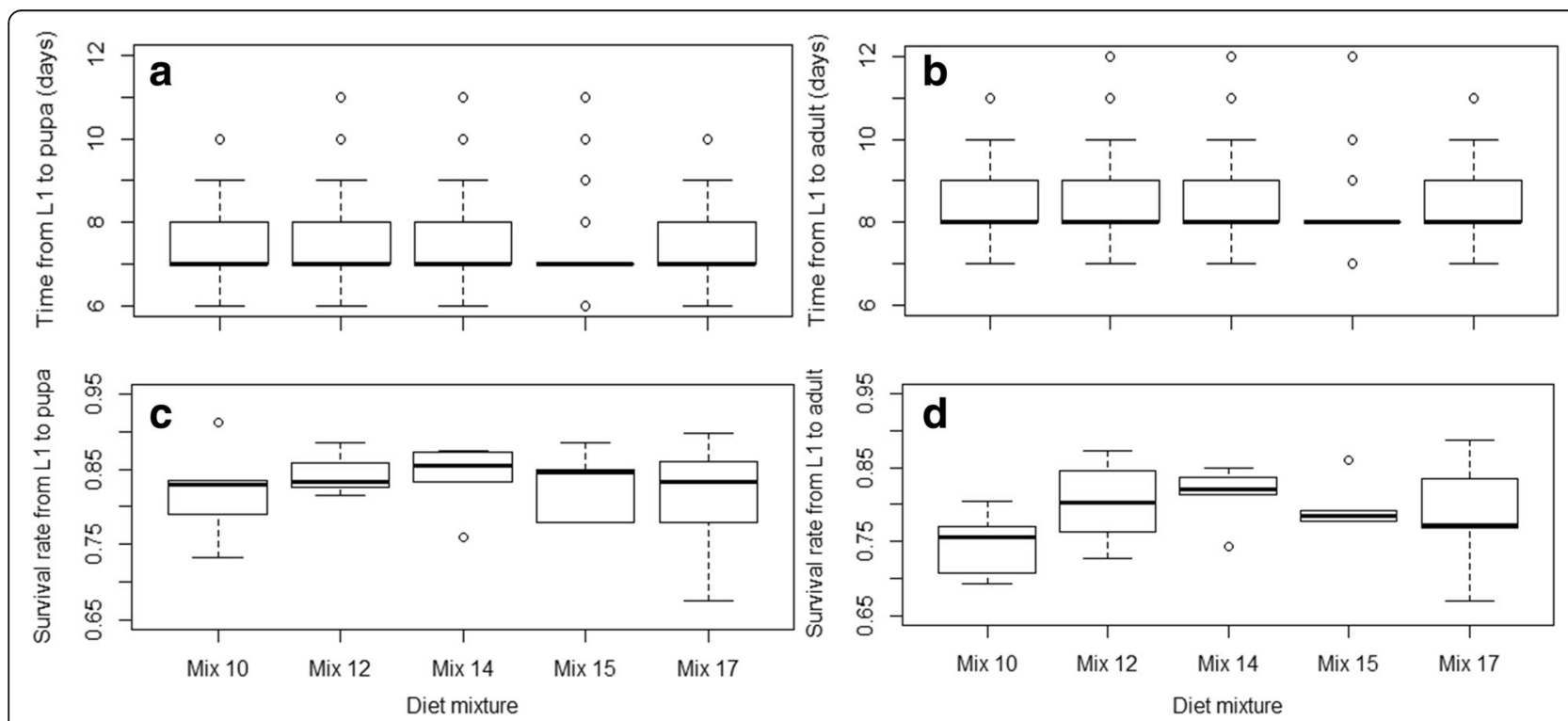

Fig. 3 Time to pupation (a) and emergence (b) and survival rates to pupa (c) and to adult (d) using promising diet mixtures: Mix 12, Mix 14, Mix 15 and Mix 17 
Table 7 Effects of four promising diets mixtures on An. arabiensis larval survival rates

\begin{tabular}{llllll}
\hline & & Estimate & SE & $z$-value & $\operatorname{Pr}(>|z|)$ \\
\hline Survival rate from & (Intercept) & 1.5267 & 0.0990 & 15.417 & $<2 \mathrm{e}-16^{* * *}$ \\
L1 to pupa & Mix 12 & 0.1652 & 0.0848 & 1.947 & 0.0515 \\
& Mix 14 & 0.1351 & 0.0844 & 1.602 & 0.1093 \\
& Mix 15 & -0.1402 & 0.0808 & -1.735 & 0.0827 \\
& Mix 17 & -0.0732 & 0.0816 & -0.898 & 0.3694 \\
Survival rate from & (Intercept) & 1.0821 & 0.0804 & 13.464 & $<2 \mathrm{e}-16^{* * *}$ \\
L1 to adult & Mix 12 & 0.3225 & 0.0762 & 4.233 & $2.31 \mathrm{e}-05^{* * *}$ \\
& Mix 14 & 0.3902 & 0.0770 & 5.064 & $4.11 \mathrm{e}-07^{* * *}$ \\
& Mix 15 & 0.1005 & 0.0737 & 1.363 & 0.1729 \\
& Mix 17 & 0.2273 & 0.0750 & 3.029 & $0.0025^{* *}$ \\
\hline
\end{tabular}

Abbreviations: $S E$ standard error, $d f$ degrees of freedom

${ }^{* *} P<0.01,{ }^{* * *} P<0.001$

control for male as and female wing length (Table $8, P>$ 0.05), except for females from Mix 14 which were larger (Table 5, $P=0.0098$ ). All of the mixtures had similar effects on egg production (Table $8, P>0.05$ ).

\section{Effects of four diets on An. arabiensis male and female survival}

The Log-rank (Mantel-Cox) test showed different survivorships between the adults from larvae fed on the different diet mixtures for females (Log-rank test, $X^{2}$ =9.6, $d f=4, P=0.0483$ ) and males (Log-rank test, $X^{2}$ $=26.1, d f=4, P=<0.0001)$. Cox proportional hazard model with Mix 10 (control) as reference showed a significant difference in the survivorship between the adults fed on the assessed diet mixtures and the control, in both sexes. For males, except for Mix 12 which had a similar effect to the control $(P=0.4443)$, Mix 14, Mix 15 and Mix 17 increased the risk of death by $1.65-, 1.36$ - and 1.33 -fold $(P<0.05)$, respectively (Table 9). Conversely for females, Mix 14 and Mix 17 significantly reduced the hazard of death by 25 and $30 \%(P<0.05)$, respectively, while Mix 12 and Mix 15 were similar to the control $(P>0.05)$ (Table 9). Overall for each treatment, males survived longer than females. The median time of survival for Mix 10 (control), Mix 12, Mix 14, Mix 15 and Mix 17, was $34,34,32,33$ and 32 days, respectively for males, and $15,16,18,18$ and 20 days, respectively for females. Over the first 30 days after emergence, the survival curves for males from the control and Mix 12 were below those of their counterparts from other mixtures (Fig. 5a). The survival curve for females from the control was the lowest followed closely by that of females from Mix 12 (Fig. 5b).

\section{Discussion}

In this study, eight diet mixtures were designed and evaluated for An. arabiensis larval development in order to identify accessible and cost-effective diet ingredients for mass rearing. The trial assessing diets without any addition of vitamin mix has revealed that this species can develop on all eight diet mixtures from L1 to the adult stage. This result suggests that all diet formulations provide the required nutrients for the larval development. The difference in efficacy between treatments may rely on the quality and quantity of nutrients, which also depend on the quality and proportion of ingredients in each mixture. This is shown by the lowest effectiveness observed with the pure tuna meal diet. The addition of vitamin mix had a positive effect resulting in a higher larval survival rate and shorter development time in all treatments as previously observed by Damiens et al. [23]. The pure diet of TM, BLP, CP, or a combination of these has been reported to be effective for Anopheles larval development, but dependent on the amount per larva per day [23, 24]. The low overall larval survival rates observed (including controls), may have been due to the low quantity of diet per larva per day [28].

Following these preliminary tests, the diet mixtures Mix 12, Mix 14, Mix 15 and Mix 17 were found to be the most promising among the eight tested mixtures, taking into account the time to pupation and the larval survival rate to adult. The evaluation of these four mixtures using larger rearing trays has revealed that all allow An. arabiensis to complete its development from L1 to adult mosquito, with fecund females. The larval survival rates to pupa and to adult corroborate the findings of Damiens et al. [23] and Khan et al. [24] who both evaluated larval diets for Anopheles species. All treatments, control included, were found to have similar or better effects on most of the assessed parameters including larval survival rates, duration of immature stages, egg production and adult body size. As fecundity and mating capabilities are known to rely on adult body size $[15,17-19,28]$ the similarity in the body size correlates with the lack of difference observed in the egg production and indicates a probable similarity in male mating capabilities. However, since the success of SIT requires high quality of produced males in terms of mating competitiveness, further study should be conducted to evaluate this parameter on mass-reared males using the different promising larval diets to definitely figure out the most suitable diet mixture.

Overall, males were found to survive longer than females as observed in other studies $[29,30]$ which addressed different objectives using the same strain as in our experiment. For all diet mixtures, males had high survival rates as more than $95 \%$ were alive after 8 days, more than $90 \%$ after 15 days, and more than 50\% after 30 days. This survivorship, higher than that observed by 
Table 8 Effects of four promising diets mixtures on An. arabiensis larval development times, adult wing length and egg production

\begin{tabular}{|c|c|c|c|c|c|c|}
\hline & & Value & SE & $d f$ & $t$-value & $P$-value \\
\hline \multirow[t]{5}{*}{ Time from L1 to pupa } & (Intercept) & 7.319910 & 0.0597 & 8206 & 122.5788 & $<0.0001^{* * *}$ \\
\hline & Mix 12 & 0.0167 & 0.0187 & 8206 & 0.8935 & 0.3716 \\
\hline & Mix 14 & -0.0412 & 0.0188 & 8206 & -2.1969 & $0.0281^{*}$ \\
\hline & Mix 15 & -0.1085 & 0.0190 & 8206 & -5.7029 & $<0.0001^{* * *}$ \\
\hline & Mix 17 & -0.0249 & 0.0189 & 8206 & -1.3141 & 0.1889 \\
\hline \multirow[t]{5}{*}{ Time from L1 to adult } & (Intercept) & 8.2610 & 0.0607 & 7822 & 136.0896 & $<0.0001^{* * *}$ \\
\hline & Mix 12 & 0.0499 & 0.0188 & 7822 & 2.6503 & $0.0081^{* *}$ \\
\hline & Mix 14 & 0.0719 & 0.0188 & 7822 & 3.8224 & $0.0001^{* * *}$ \\
\hline & Mix 15 & -0.0633 & 0.0191 & 7822 & -3.3139 & $0.0009^{* * *}$ \\
\hline & Mix 17 & 0.0305 & 0.0189 & 7822 & 1.6075 & 0.1080 \\
\hline \multirow[t]{5}{*}{ Male wing length } & (Intercept) & 2.9150 & 0.0242 & 241 & 120.4781 & $<0.0001^{* * *}$ \\
\hline & Mix 12 & 0.0066 & 0.0161 & 241 & 0.4116 & 0.6810 \\
\hline & Mix 14 & 0.0281 & 0.0161 & 241 & 1.7438 & 0.0825 \\
\hline & Mix 15 & -0.0020 & 0.0161 & 241 & -0.1241 & 0.9013 \\
\hline & Mix 17 & -0.0243 & 0.0161 & 241 & -1.5091 & 0.1326 \\
\hline \multirow[t]{5}{*}{ Female wing length } & (Intercept) & 3.1142 & 0.0205 & 241 & 152.2137 & $<0.0001^{* * *}$ \\
\hline & Mix 12 & 0.0069 & 0.0167 & 241 & 0.4126 & 0.6803 \\
\hline & Mix 14 & 0.0434 & 0.0167 & 241 & 2.6051 & $0.0098^{* *}$ \\
\hline & Mix 15 & 0.0277 & 0.0167 & 241 & 1.6629 & 0.0976 \\
\hline & Mix 17 & -0.0028 & 0.0167 & 241 & -0.1704 & 0.8648 \\
\hline \multirow[t]{5}{*}{ Egg production } & (Intercept) & 3132.6667 & 492.5974 & 8 & 6.3595 & $0.0002^{* * *}$ \\
\hline & Mix 12 & -1243.6667 & 546.1322 & 8 & -2.2772 & 0.0523 \\
\hline & Mix 14 & -226.3333 & 546.1322 & 8 & -0.4144 & 0.6894 \\
\hline & Mix 15 & -186.3333 & 546.1322 & 8 & -0.3412 & 0.7418 \\
\hline & Mix 17 & -346.3333 & 546.1322 & 8 & -0.6342 & 0.5437 \\
\hline
\end{tabular}

Abbreviations: $S E$ standard error, $d f$ degrees of freedom

${ }^{*} P<0.05,{ }^{* * P}<0.01,{ }^{* * *} P<0.001$

Khan et al. [24], could be an advantage leading to maximised opportunities for mating activities in the field. Indeed, according to Sawadogo et al. [31], 4-8 days-old is optimum for male Anopheles gambiae (s.s.) to successfully inseminate females. More than $50 \%$ survival was recorded after 15 days in females from all diet mixtures. This result showed that a maximum egg production could be achieved in the mass rearing unit from females from all treatments. Indeed, the largest number of eggs has been found to be produced within the mass rearing cage during the first 15 days [32].

The similar outcomes of the assessed mixtures may be related to their similarity in the composition of nutrients that influence mosquito life history traits. Nutritional requirements of mosquito larvae are known to include amino acids, such as asparagine, arginine, glycine, histidine, isoleucine, leucine, lysine, methionine, phenylalanine, proline, serine, threonine, tryptophan and valine [20, 33, 34]. These elements could be provided by each ingredient because they are found in all organisms in the form of proteins [21, 35]. In addition, the VM provides all essential vitamins for optimal development such as thiamine, riboflavin, pyridoxine, nicotinic acid, calcium pantothenate, folic acid, biotin and choline [20]. Moreover, fatty acids and particularly polyunsaturated fatty acids (PUFAs), are known to play an important role in mosquito biology [3640]. The PUFAs linoleic acid (LA, 18: 2w6), alpha-linolenic acid (ALA, 18: 3w3), arachidonic acid (AA, 20: 4w6), eicosapentaenoic acid (EPA, 20: 5w3) and docosahexaenoic acid (DHA, 22: 6w3), DGLA are essential for both larval and adult life traits as they enter into the structural composition of the cell membrane, interact with the immune system and in reproduction, and enhance survival and flight activities. The BLP, the TM and CP provide ample amounts of $\mathrm{C}_{18}$ and $\mathrm{C}_{20-22}$ PUFAs [23, 41].To develop the SIT package to control An. arabiensis, a standard larval diet has been developed at the Insect Pest Control Laboratory of the Joint FAO/IAEA Division of Nuclear 

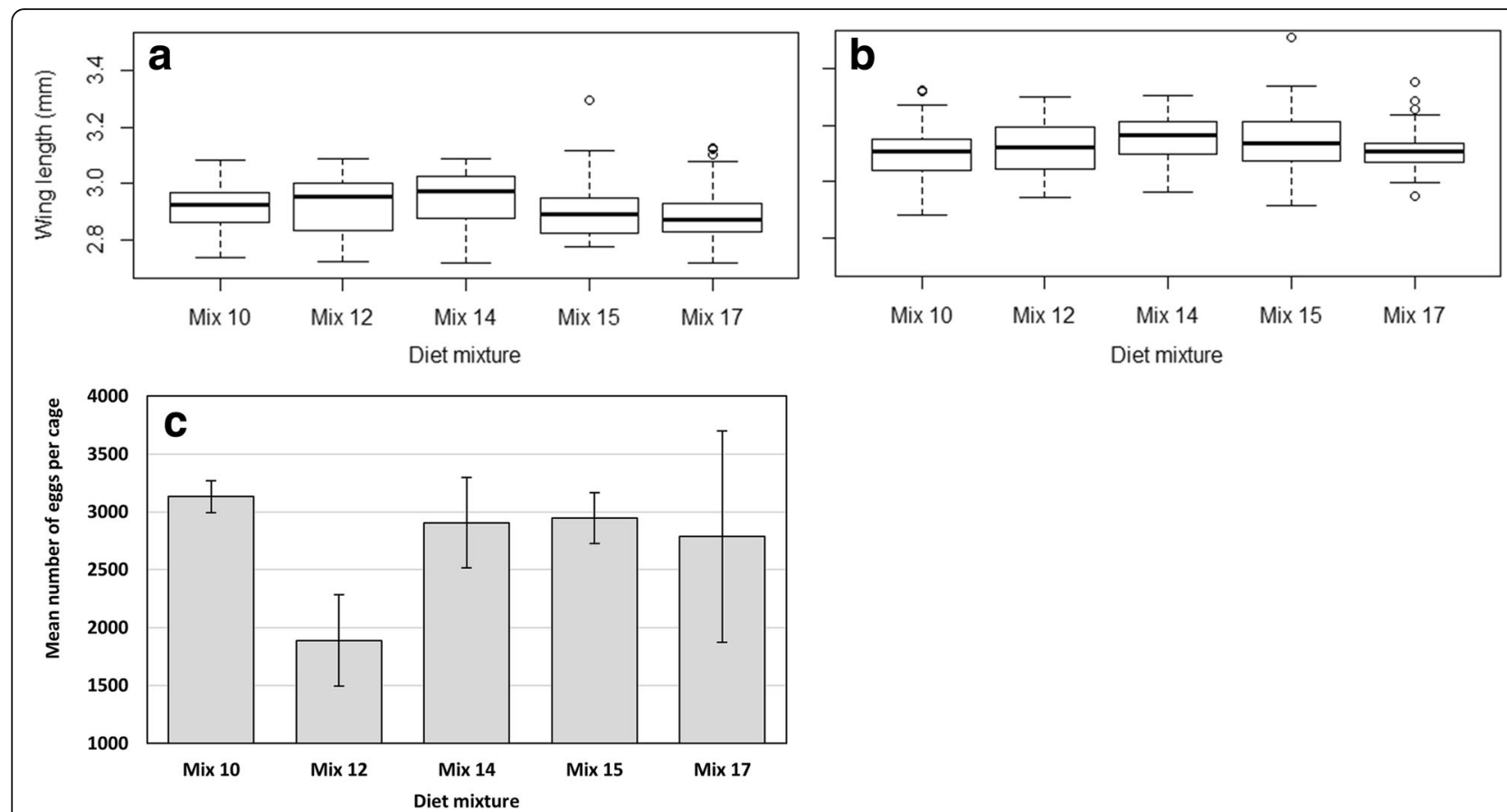

Fig. 4 Anopheles arabiensis male (a) and female (b) wing length, egg production (c) using promising diets mixtures: Mix 12, Mix 14, Mix 15 and Mix 17

Techniques in Food and Agriculture, composed of 50\% TM (5 g/l) and 50\% BLP (5 g/l) supplied with vitamin mix $(4.6 \mathrm{~g} / \mathrm{l})$ as an additive [23]. Although effective in rearing high-quality adults, this diet relies on the availability of the expensive ingredient BLP, of which current and future availability are of concern. Indeed, this ingredient is more than 78-fold more costly than the TM and alone comprises about $99 \%$ of the global cost of the mixture (without any additive) (Table 1). Our study has demonstrated that four different diet mixtures that are 40-92\% cheaper can result in positive mosquito life history traits, indicating that this mosquito species can be effectively mass reared with a significant reduction in cost (Table 5). The best mixtures are

Table 9 Effects of four promising diets mixtures on An. arabiensis male and female longevity

\begin{tabular}{lllllll}
\hline & Diet & Coef & Exp (coef) & SE (Coef) & $z$-value & $\operatorname{Pr}(>|z|)$ \\
\hline Males & Mix 12 & -0.1031 & 0.9020 & 0.1348 & -0.765 & 0.4443 \\
& Mix 14 & 0.5026 & 1.6529 & 0.1359 & 3.697 & $0.0002^{* * *}$ \\
& Mix 15 & 0.3088 & 1.3618 & 0.1345 & 2.296 & $0.0217^{*}$ \\
& Mix 17 & 0.2872 & 1.3327 & 0.1346 & 2.134 & $0.0328^{*}$ \\
Females & Mix 12 & -0.1623 & 0.8502 & 0.1297 & -1.251 & 0.2109 \\
& Mix 14 & -0.3281 & 0.7203 & 0.1298 & -2.528 & $0.0115^{*}$ \\
& Mix 15 & -0.2158 & 0.8059 & 0.1296 & -1.665 & 0.0958. \\
& Mix 17 & -0.3500 & 0.7047 & 0.1290 & -2.714 & $0.0067^{* *}$ \\
\hline
\end{tabular}

Abbreviations: Coef coefficient, Exp Exponential, SE standard error ${ }^{*} P<0.05,{ }^{* *} P<0.01,{ }^{* * *} P<0.001$ those which include fewer ingredients. In this context, Mix 15 and Mix 17, which contain four ingredients (TM, BLP, $\mathrm{BY}$ and $\mathrm{CP}$ ), are more cumbersome to produce and more expensive than Mix 12 (TM, BLP and BY) and Mix 14 (TM, BY and CP). Moreover, taking into account the availability concern of BLP and the cost reduction in each diet mixture in relation to the control (Table 5), we recommend using Mix 14, which costs $92 \%$ less than the original diet and where BLP has been fully removed.

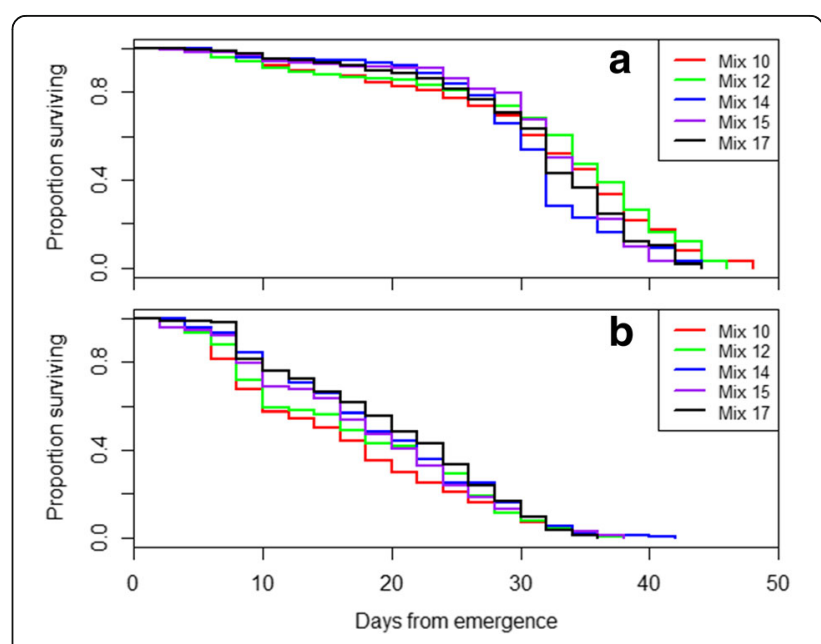

Fig. 5 Survival curves of An. arabiensis males (a) and females (b) following the larval diet mixtures: Mix 12, Mix 14, Mix 15 and Mix 17 


\section{Conclusions}

The present study investigated eight larval diet mixtures in order to find optimal laval diets for An. arabiensis mass rearing. Four diet mixtures, 40-92\% cheaper than the IAEA diet, resulted in positive life history traits. The mixture comprising $\mathrm{TM}+\mathrm{BY}+\mathrm{CP}$ is the preferred choice as it does not include BLP and reduces the cost by $92 \%$ compared to the IAEA diet. These findings contribute to the development of effective, affordable, and environmentally friendly techniques to reduce $A n$. arabiensis populations and to thus protect the human population from both the biting nuisance of this species and the deadly disease that it transmits.

\section{Abbreviations}

BLP: Bovine liver powder; BY: Brewer's yeast; CP: Chickpea; FAO: Food and agriculture organization; IAEA: International atomic energy agency; IPCL: Insect pest control laboratory; Mix: Mixture; SIT: Sterile insect technique; TM: Tuna meal; VM: Vitamin mix

\section{Acknowledgements}

The authors acknowledge Institut de Recherche en Science de la Santé, Direction Régionale de l'Ouest (IRSS/DRO), Burkina Faso and Insect Pest Control Laboratory (IPCL) of the Joint FAO/IAEA Division of Nuclear Techniques in Food and Agriculture.

\section{Funding}

This work has been funded by the Joint FAO/IAEA Division of Nuclear Techniques in Food and Agriculture.

\section{Availability of data and materials}

The data supporting the conclusions of this study are provided within the article. All datasets generated and analysed during the current study are available from the corresponding author upon reasonable request.

\section{Authors' contributions}

NSBS performed the experiments, the data analysis and drafted the manuscript which was critically revised by KRD, HM, HY, OG, AD, AS, JB and JRLG. HM and MW participated in experiments. JB contributed to analysing and interpreting the data. JRLG conceived the study and supervised all of the work. All authors read and approved the final manuscript.

\section{Ethics approval and consent to participate}

Not applicable.

\section{Consent for publication}

Not applicable.

\section{Competing interests}

The authors declare that they have no competing interests.

\section{Publisher's Note}

Springer Nature remains neutral with regard to jurisdictional claims in published maps and institutional affiliations.

\section{Author details}

'Insect Pest Control Laboratory, International Atomic Energy Agency, Joint FAO/IAEA Division of Nuclear Techniques in Food and Agriculture, Vienna, Austria. ${ }^{2}$ Institut de Recherche en Sciences de la Santé/Direction Régionale de l'Ouest, Bobo-Dioulasso, Burkina Faso. ${ }^{3}$ Laboratoire d'Entomologie Fondamentale et Appliquée, Université Ouaga 1 Joseph Ki-Zerbo, Ouagadougou, Burkina Faso. ${ }^{4}$ Institut de Recherche Agricole pour le Développement, Yaoundé, Cameroon.
Received: 28 August 2017 Accepted: 21 November 2017

Published online: 22 December 2017

\section{References}

1. WHO. World malaria report 2015. Geneva: WHO; 2015.

2. Coetzee M, Craig M, Le Sueur D. Distribution of African malaria mosquitoes belonging to the Anopheles gambiae complex. Parasitol Today. 2000;16:747.

3. Dabiré KR, Sawadogo PS, Hien DF, Bimbilé-Somda NS, Soma DD, Millogo A, et al. Occurrence of natural Anopheles arabiensis swarms in an urban area of Bobo-Dioulasso city, Burkina Faso, West Africa. Acta Trop. 2014;132S:S35-41.

4. Jones $\mathrm{CM}$, Toé $\mathrm{KH}$, Sanou A, Namountougou M, Hughes A, Diabaté A, et al. Additional selection for insecticide resistance in urban malaria vectors: DDT resistance in Anopheles arabiensis from Bobo-Dioulasso, Burkina Faso. PLoS One. 2012;7(9):e45995.

5. White GB. The Anopheles gambiae Complex and malaria transmission around Kisumu, Kenya. Trans R Soc Trop Med Hyg. 1972:66:572-81.

6. White GB. Anopheles gambiae Complex and disease transmission in Africa. Trans R Soc Trop Med Hyg. 1974;68:278-301.

7. Sharp BL, Le Sueur D. Behavioural variation of Anopheles arabiensis (Diptera: Culicidae) populations in Natal, South Africa. Bull Entomol Res. 1991;81:10710 .

8. Coluzzi M, Sabatini A, Petrarca V, Di Deco MA. Chromosomal differentiation and adaptation to human environments in the Anopheles gambiae Complex. Trans R Soc Trop Med Hyg. 1979;73:483-97.

9. Ameneshewa B, Service MW. Resting habits of Anopheles arabiensis in the awash river valley of Ethiopia. Ann Trop Med Parasitol. 1996;90:515-21.

10. Benedict MQ, Robinson AS. The first releases of transgenic mosquitoes: an argument for the sterile insect technique. Trends Parasitol. 2003;19:349-55.

11. Robinson AS, Knols BGJ, Voigt G, Hendrichs JP. Conceptual framework and rationale. Malar J. 2009:8:S1.

12. Chambers GM, Klowden MJ. Correlation of nutritional reserves with a critical weight for pupation in larval Aedes aegypti mosquitoes. J Am Mosq Control Assoc. 1990;6:394-9.

13. Agnew $P$, Hide $M$, Sidobre $C$, Michalakis $Y$. A minimalist approach to the effects of density-dependent competition on insect life-history traits. Ecol Entomol. 2002;27:396-402.

14. Gilles JRL, Lees RS, Soliban SM, Benedict MQ. Density-dependent effects in experimental larval populations of Anopheles arabiensis (Diptera: Culicidae) can be negative, neutral, or overcompensatory depending on density and diet levels. J Med Entomol. 2011:48:296-304.

15. Araujo MDS, Gil LHS, Silva AA. Larval food quantity affects development time, survival and adult biological traits that influence the vectorial capacity of Anopheles darlingi under laboratory conditions. Malar J. 2012;11:261.

16. Briegel H. Fecundity, metabolism, and body size in Anopheles (Diptera, Culicidae), vectors of malaria. J Med Entomol. 1990;27:839-50.

17. Ng'habi KR, John B, Nkwengulila G, BGJ K, Killeen GF, Ferguson HM. Effect of larval crowding on mating competitiveness of Anopheles gambiae mosquitoes. Malar J. 2005:4:49.

18. Takken W, Smallegange RC, Vigneau A, Johnston V, Brown M, Mordue Luntz AJ, et al. Larval nutrition differentially affects adult fitness and Plasmodium development in the malaria vectors Anopheles gambiae and Anopheles stephensi. Parasit Vectors. 2013;6:345.

19. Vantaux A, Ouattarra I, Lefèvre T, Dabiré KR. Effects of larvicidal and larval nutritional stresses on Anopheles gambiae development, survival and competence for Plasmodium falciparum. Parasit Vectors. 2016:9:226.

20. Kleinjan JE, Dadd RH. Vitamin requirements of the larval mosquito, Culex pipiens. Ann Entomol Soc Am. 1977;70:541-3.

21. Merritt RW, Dadd RH, Walker ED. Feeding behaviour, natural food, and nutritional relationships of larval mosquitoes. Annu Rev Entomol. 1992; 37:349-76.

22. Yahouédo GA, Djogbénou L, Saïzonou J, Assogba BS, Makoutodé M, Gilles $J R L$, et al. Effect of three larval diets on larval development and male sexual performance of Anopheles gambiae s.s. Acta Trop. 2014;132S:S96-S101.

23. Damiens D, Benedict MQ, Wille M, Gilles JRL. An inexpensive and effective larval diet for Anopheles arabiensis (Diptera: Culicidae): eat like a horse, a bird or a fish? J Med Entomol. 2012;49:1001-11.

24. Khan I, Farid A, Zeb A. Development of inexpensive and globally available larval diet for rearing Anopheles stephensi (Diptera: Culicidae) mosquitoes. Parasit Vectors. 2013;6:90. 
25. Puggioli A, Balestrino F, Damiens D, Lees RS, Soliban SM, Madakacherry O, et al. Efficiency of three diets for larval development in mass rearing Aedes albopictus (Diptera: Culicidae). J Med Entomol. 2013;50:819-25.

26. Damiens D, Soliban SM, Balestrino F, Alsir R, Vreysen MJB, Gilles JRL. Different blood and sugar feeding regimes affect the productivity of Anopheles arabiensis colonies (Diptera: Culicidae). J Med Entomol. 2013;50:336-43.

27. R: A language and environment for statistical computing. Version 3.2.5 https://cran.r-project.org/src/base/R-3/

28. Almerão MP, Fagundes NJ, de Araújo PB, Verne S, Grandjean F, Bouchon D, et al. First record of Wolbachia in South American terrestrial isopods: prevalence and diversity in two species of Balloniscus (Crustacea, Oniscidea). Genet Mol Biol. 2012;35:980-9.

29. Maïga $H$, Damiens $D$, Diabaté $A$, Dabiré RK, Ouédraogo GA, Lees RS, et al. Large-scale Anopheles arabiensis egg quantification methods for massrearing operations. Malar J. 2016;15:72.

30. Mamai W, Lees RS, Maiga H, Gilles JRL. Reusing larval rearing water and its effect on development and quality of Anopheles arabiensis mosquitoes. Malar J. 2016;15:169

31. Sawadogo SP, Diabaté A, Toé HK, Sanon A, Lefevre T, Baldet T, et al. Effects of age and size on Anopheles gambiae s.s. Male mosquito mating success. J Med Entomol. 2013;50:285-93.

32. Mamai W, Bimbile-Somda NS, Maiga H, Juarez JG, Muosa ZAl, Ali AB, et al. Optimization of mosquito egg production under mass rearing setting: effects of cage volume, blood meal source and adult population density for the malaria vector, Anopheles arabiensis. Malar J. 2017;16:41.

33. Dadd RH, Kleinjan JE, Sneller VP. Development of several species of mosquito larvae in fully defined dietary media: preliminary evaluation. Mosq News. 1977:37:699-703.

34. Dadd RH, Kleinjan JE. Chemically defined dietary media for larvae of the mosquito Culex pipiens (Diptera: Culicidae): effects of colloid texturizers. J Med Entomol. 1976;13:285-91.

35. Zaviezo D, Dale N. Nutrient content of tuna meal. Poult Sci. 1994;73:916-8.

36. Asman SM, Dadd RH, Kleinjan JE. Essential fatty acids as diet components for competitive mating of Culex tarsalis in the field. NAL/USDA, Mosq Control Res Annu Rep. 1985:43-5.

37. Dadd RH, Kleinjan JE, Asman SM. Eicosapentaenoic acid in mosquito tissues: differences between wild and laboratory-reared adults. Environ Entomol. 1988:17:172-80

38. Dadd RH, Asman SM, Kleinjan JE. Essential fatty acid status of laboratoryreared mosquitos improved by supplementing crude larval foods with fish oils. Entomol Exp Appl. 1989;52:149-58.

39. Dadd RH, Kleinjan JE, Stanley-Samuelson DW. Polyunsaturated fatty acids of mosquitos reared with single dietary polyunsaturates. Insect Biochem. 1987:17:7-16.

40. Dadd RH. Essential fatty acids for mosquitoes, other insects and vertebrates. In: Ghaskaran G, Friedman S, Rodriguez JG, editors. Current Topics in Insect Endocrinology and Nutrition. New York: Plenum Publishing Corp; 1981. p. 189-214.

41. Sanders TAB. Essential and trans-fatty acids in nutrition. Nutr Res Rev. 1988:1:57-8.

\section{Submit your next manuscript to BioMed Central and we will help you at every step:}

- We accept pre-submission inquiries

- Our selector tool helps you to find the most relevant journal

- We provide round the clock customer support

- Convenient online submission

- Thorough peer review

- Inclusion in PubMed and all major indexing services

- Maximum visibility for your research

Submit your manuscript at www.biomedcentral.com/submit

C Biomed Central 